\title{
On the debated role of temporo-parietal dysfunction in patients with basal ganglia neglect
}

\author{
Luca F. Ticini* ${ }^{*+}$ \\ The Italian Society for Neuroaesthetics 'Semir Zeki', Trieste, Italy \\ *Correspondence: luca.ticini@gmail.com \\ Edited by: \\ Nuno Sousa, University of Minho, Portugal \\ Reviewed by: \\ Magdalena Chechlacz, University of Oxford, UK \\ ${ }^{\dagger}$ Present address: \\ Luca F. Ticini, Wellcome Laboratory of Neurobiology, University College London, London, UK
}

Keywords: spatial neglect, visual extinction, perfusion-weighted imaging, temporoparietal junction, basal ganglia

A lively debate in neuropsychology addresses the question of which neural structure, when damaged, causes spatial neglect. Behaviorally, individuals with spatial neglect show several disturbances including the spontaneous deviation of head and eyes toward the ipsilesional (right) side as well as inattention to objects and persons located on the contralesional side of space (for a review, see Karnath and Rorden, 2012). Occasionally, neglect is associated with visual extinction, a deficit in the ability to simultaneously perceive multiple competing stimuli (Oppenheim, 1885). Neglect and extinction show obvious differences and several scholars have argued that they represent separate deficits (Bisiach, 1991; Vallar et al., 1994; Driver et al., 1997; Milner, 1997; Karnath and Rorden, 2012). Moreover, they seem to have anatomically related but (partly) separated neural representations (Karnath et al., 2003). In particular, spatial neglect is provoked by damage to a spatially distributed right hemisphere network of cortical and subcortical structures that directly or remotely impairs brain areas dedicated to the orientation of visuospatial attention (e.g., Karnath et al., 2009; Thiebaut de Schotten et al., 2012; for a recent meta-analysis, see Molenberghs et al., 2012 and comments in Bartolomeo, 2012). Extinction, on the other hand, occurs when the right temporo-parietal cortex is directly damaged (Karnath et al., 2003; see also Molenberghs et al., 2012, Figure 3) or experimentally deactivated by transcranial magnetic stimulation (Meister et al., 2006).
Subcortical lesions can also lead to neglect (Demeurisse et al., 1997; Hillis et al., 2005) and extinction (Ticini et al., 2010a) when they compromise the functioning of districts located far from the neural loss itself, through pathophysiological mechanisms such as hypometabolism (Yasaka et al., 1998), hypoperfusion (Hillis et al., 2000), or diaschisis (Monakow, 1914; Kempler et al., 1988; Price et al., 2001; Finger et al., 2004). Indeed, at times, neglect and extinction are associated with areas of dysfunctional but structurally intact tissue beyond the structural damage itself (e.g., Hillis et al., 2001, 2005; Karnath et al., 2005; Ticini et al., 2010a; Khurshid et al., 2012). How these brain regions are identified?

In the acute stage of a stroke, DiffusionWeighted MR Imaging (or T2-weighted fluid-attenuated inversion-recovery sequences if imaging is conducted $48 \mathrm{~h}$ or later after stroke onset) is used to reveal the irreversibly damaged areas (Fisher, 1995). Perfusion-Weighted Imaging (PWI) is employed, instead, to identify the whole extent of dysfunctional tissue within and beyond the lesion. The mismatch between diffusion and perfusion maps ("diffusion-perfusion mismatch"; see Neumann-Haefelin et al., 1999) spots areas of functional deficits besides the structural damage (e.g., the tissue that receives enough blood supply to remain structurally intact but not enough nourishment and oxygen to function normally) that are potentially recoverable if blood flow is restored by medical intervention (Beaulieu et al., 1999). As a matter of fact, recent results have shown that restoring blood flow ameliorates different types of neglect, thus suggesting the factual role of dysfunctional brain areas in this syndrome (Khurshid et al., 2012). Nonetheless, some uncertainties still endure. In the following lines I aim at arguing against the role of the temporo-parietal junction in subcortical neglect, suggesting instead that this area is dysfunctional in extinction, in conformity with previous studies (e.g., Karnath et al., 2003; Meister et al., 2006).

In a paper published in the journal Brain, Karnath et al. (2005) employed spatial normalization and symmetric voxelwise inter-hemispheric comparisons, to precisely locate the functional deficits associated with neglect in patients with subcortical sub/acute lesions. The authors found that: "strokes centering on the right basal ganglia which provoke spatial neglect induce abnormal perfusion in a circumscribed area of intact cortex that typically involves those three regions that have previously been described to provoke spatial neglect when damaged directly by cortical infarction: the superior temporal gyrus, the inferior parietal lobule and the inferior frontal gyrus" (i.e., the inferior frontal and temporo-parietal cortices; see their Figure 3). They further concluded that: "spatial neglect following a right basal ganglia lesion typically is caused by the dysfunction of (part of) these specific cortical areas." To investigate the abnormally perfused tissue in basal ganglia neglect, Karnath et al. (2005) "compared perfusion abnormalities in the patient groups with and without spatial neglect." For this purpose, they subtracted the diffusionperfusion mismatch maps of 5 control 
patients without neglect from those of 5 individuals with neglect.

It is worth noting at this point that to identify brain-behavior correlations in stroke patients, it is common to employ the well-established procedure that consists in subtracting the images of the group without neurological or neuropsychological symptoms from the images of the group who has those symptoms (Rorden and Karnath, 2004). Evidently, a critical prerequisite for the successful application of this technique is the selection of appropriate patient groups. However, in Karnath et al. the groups studied were not selected according to this procedure: indeed, 4 of the neglect patients also had visual extinction. As such, they were later used by Ticini et al. (2010a) who subtracted diffusionperfusion mismatch maps of 5 patients with only neglect from those of 8 individuals with neglect and extinction to find that visual extinction following a right basal ganglia lesion is caused by the dysfunction of the temporo-parietal area (for its involvement in extinction, see also de Haan et al., 2012). Noteworthy, in Ticini et al. (2010b) patients E1, E2, E4, and E5 (see their Table 1)-who belonged to the group with neglect and extinctionand patients N4-who belonged to the group with only neglect-were the 5 individuals "with neglect" studied by Karnath et al. (2005). In other words, there is the possibility that, by subtracting the perfusion maps of control patients from that of the 5 neglect individuals of which 4 also had extinction, Karnath et al. overestimated the dysfunctional area associated with neglect, by extending it to the temporo-parietal cortex in reality associated with extinction. The fact that patient N4 (i.e., the only neglect patient without extinction) "did not show relevant cortical perfusion abnormalities in addition to her lesion" (Karnath et al., 2005) supports this hypothesis.

In conclusion, these results juxtaposed with each other seem to suggest that visual extinction (rather than spatial neglect) following a sub/acute lesion in the right basal ganglia is caused by the dysfunction of the temporo-parietal cortex. The generalization of these results is limited by the small group size and the absence of information about spontaneous recovery at different stages after stroke-onset (as for instance in Khurshid et al., 2012). Nonetheless, the information provided here may contribute to an incremental understanding of the role of perfusion deficits in spatial neglect and extinction through a better characterization of potentially salvageable brain tissue associated with these neuropsychological deficits.

\section{ACKNOWLEDGMENTS}

I thank Dr. Michel Thiebaut de Schotten and the reviewer for their useful comments on the manuscript.

\section{REFERENCES}

Bartolomeo, P. (2012). The elusive nature of white matter damage in anatomo-clinical correlations. Front. Hum. Neurosci. 6:229. doi: 10.3389/fnhum.2012.00229

Beaulieu, C., de Crespingy, A., Tong, D. C., Mosely, M. E., Albers, G. W., and Marks, M. P. (1999). Longitudinal magnetic resonance imaging study of perfusion and diffusion in stroke: Evolution of volume and correlation with clinical outcome. Ann. Neurol. 46, 568-578. doi: 10.1002/15318249(199910)46:4<568::AID-ANA4>3.0.CO;2-R

Bisiach, E. (1991). "Extinction and neglect: same or different," in Brain and Space ed J. Paillard (Oxford: Oxford University Press), 251-257.

de Haan, B., Karnath, H.-O., and Driver, J. (2012). Mechanisms and anatomy of unilateral extinction after brain injury. Neuropsychologia 50, 1045-1053. doi: 10.1016/j.neuropsychologia.2012.02.015

Demeurisse, G., Hublet, C., Paternot, J., Colson, C., and Serniclaes, W. (1997). Pathogenesis of subcortical visuo-spatial neglect. A HMPAO SPECT study. Neuropsychologia 35, 731-735. doi: 10.1016/S0028-3932(96)00126-1

Driver, J., Mattingley, J. B., Rorden, C., and Davis, G. (1997). "Extinction as a paradigm measure of attentional bias and restricted capacity following brain injury," in Parietal Lobe Contributions to Orientation in 3D Space, eds $\mathrm{P}$. Thier and H.-O. Karnath (Berlin: Springer-Verlag), 401-430.

Finger, S., Koehler, P. J., and Jagella, C. (2004). The Monakow concept of diaschisis: origins and perspectives. Arch. Neurol. 61, 283-288. doi: 10.1001/archneur.61.2.283

Fisher, M. (1995). Diffusion and perfusion imaging for acute stroke. Surg. Neurol. 43, 606-609. doi: 10.1016/0090-3019(95)00015-1

Hillis, A. E., Barker, P. B., Beauchamp, N. J., Gordon, B., and Wityk, R. J. (2000). MR perfusion imaging reveals regions of hypoperfusion associated with aphasia and neglect. Neurology 55, 782-788. doi: 10.1212/WNL.55.6.782

Hillis, A. E., Newhart, M., Heidler, J., Barker, P. B., Herskovits, E. H., and Degaonkar, M. (2005). Anatomy of spatial attention: insights from perfusion imaging and hemispatial neglect in acute stroke. J. Neurosci. 25, 3161-3167. doi: 10.1523/JNEUROSCI.4468-04.2005
Hillis, A. E., Wityk, R. J., Tuffiash, E., Beauchamp, N. J., Jacobs, M. A., Barker, P. B., et al. (2001). Hypoperfusion of Wernicke's area predicts severity of semantic deficit in acute stroke. Ann. Neurol. 50, 561-566. doi: 10.1002/ ana.1265

Karnath, H.-O., Himmelbach, M., and Küker, W. (2003). The cortical substrate of visual extinction. Neuroreport 14, 437-442. doi: 10.1097/00001756200303030-00028

Karnath, H.-O., and Rorden, C. (2012). The anatomy of spatial neglect. Neuropsychologia 50, 1010-1017. doi: 10.1016/j.neuropsychologia.2011.06.027

Karnath, H.-O., Rorden, C., and Ticini, L. F. (2009). Damage to white matter fiber tracts in acute spatial neglect. Cereb. Cortex 19, 2331-2337. doi: $10.1093 /$ cercor/bhn250

Karnath, H.-O., Zopf, R., Johannsen, L., Fruhmann Berger, M., Nägele, T., and Klose, U. (2005). Normalized perfusion MRI to identify common areas of dys- function: patients with basal ganglia neglect. Brain 128, 2462-2469. doi: 10.1093/brain/awh629

Kempler, D., Metter, E. J., Jackson, C. A., Hanson, W. R., Riege, W. H., Mazziotta, J. C., et al. (1988). Disconnection and cerebral metabolism. The case of conduction aphasia. Arch Neurol. 45, 275-279. doi: 10.1001/archneur.1988.005202700 49020

Khurshid, S., Trupe, L. A., Newhart, M., Davis, C., Molitoris, J. J., Medina, J., et al. (2012). Reperfusion of specific cortical areas is associated with improvement in distinct forms of hemispatial neglect. Cortex 48, 530-539. doi: 10.1016/j.cortex.2011.01.003

Meister, I. G., Wienemann, M., Buelte, D., Grünewald, C., Sparing, R., Dambeck, N., et al. (2006) Hemiextinction induced by transcranial magnetic stimulation over the right temporo-parietal junction. Neuroscience 142, 119-123. doi: 10.1016/j.neuroscience.2006.06.023

Milner, A. D. (1997). "Neglect, extinction, and the cortical streams of visual processing," in Parietal Lobe Contributions to Orientation in 3D Space eds P. Thier and H.-O. Karnath (Heidelberg: SpringerVerlag), 3-22.

Molenberghs, P., Sale, M. V., and Mattingley, J. B. (2012). Is there a critical lesion site for unilateral spatial neglect. A meta-analysis using activation likelihood estimation. Front. Hum. Neurosci. 6:78. doi: 10.3389/fnhum.2012.00078

Monakow, C. V. (1914). Die Lokalisation im Grosshirn und der Funktion durch kortikale Herde. Wiesbaden: Verlag von J. F. Bergmann.

Neumann-Haefelin, T., Wittsack, H. J., Wenserski, F., Siebler, M., Seitz, R. J., Mödder, U., et al. (1999). Diffusion- and perfusion-weighted MRI The DWI/PWI mismatch region in acute stroke. Stroke 30, 1591-1597. doi: 10.1161/01.STR.30. 8.1591

Oppenheim, H. (1885). Über eine durch eine klinisch bisher nicht verwerthete Untersuchungsmethode ermittelte Form der Sensibilitätsstörung bei einseitigen Erkrankungen des Grosshirns. Neurol. Centralbl. 4, 529-532.

Price, C. J., Warburton, E. A., Moore, C. J., Frackowiak, R. S. J., and Friston, K. J. (2001). Dynamic diaschisis: anatomically remote and context-sensitive human brain 
lesions. J. Cogn. Neurosci. 13, 419-429. doi: 10.1162/08989290152001853

Rorden, C., and Karnath, H.-O. (2004). Using human brain lesions to infer function: A relic from a past era in the fMRI age. Nat. Rev. Neurosci. 5, 813-819. doi: $10.1038 /$ nrn 1521

Thiebaut de Schotten, M., Tomaiuolo, F., Aiello, M., Merola, S., Silvetti, M., Lecce, F., et al. (2012). Damage to white matter pathways in subacute and chronic spatial neglect: a group study and 2 single-case studies with complete virtual "in vivo" tractography dissection. Cereb. Cortex doi: 10.1093/cercor/bhs351. [Epub ahead of print]. Ticini, L. F., de Haan, B., Klose, U., Naegele, T., and Karnath, H.-O. (2010a). The role of the temporo-parietal cortex in subcortical visual extinction. J. Cogn. Neurosci. 22, 2141-2150. doi: 10.1162/jocn.2009.21315
Ticini, L. F., Klose, U., Naegele, T., and Karnath, H.-O. (2010b). Perfusion imaging in pusher syndrome to investigate the neural substrates involved in controlling upright body position. PLoS ONE 4:e5737. doi: 10.1371/journal.pone. 0005737

Vallar, G., Rusconi, M. L., Bignamini, L., Geminiani, G., and Perani, D. (1994). Anatomical correlates of visual and tactile extinction in humans: a clinical CT scan study. J. Neurol. Neurosurg. Psychiatry 57, 464-470. doi: 10.1136/jnnp.57. 4.464

Yasaka, M., Read, S. J., O’Keefe, G. J., Egan, G. F., Pointon, O., McKay, W. J., et al. (1998). Positron emission tomography in ischaemic stroke: cerebral perfusion and metabolism after stroke onset. J. Clin. Neurosci. 5, 413-416. doi: 10.1016/S09675868(98)90274-0
Received: 11 September 2013; accepted: 01 November 2013; published online: 18 November 2013.

Citation: Ticini LF (2013) On the debated role of temporo-parietal dysfunction in patients with basal ganglia neglect. Front. Behav. Neurosci. 7:168. doi: 10.3389/fnbeh.2013.00168

This article was submitted to the journal Frontiers in Behavioral Neuroscience.

Copyright (C) 2013 Ticini. This is an open-access article distributed under the terms of the Creative Commons Attribution License (CC BY). The use, distribution or reproduction in other forums is permitted, provided the original author(s) or licensor are credited and that the original publication in this journal is cited, in accordance with accepted academic practice. No use, distribution or reproduction is permitted which does not comply with these terms. 